\title{
Effect of Solanium melongena fruits supplemented diet on hyperglycemia, overweight, liver function and dyslipidemia in male New Zealand rabbits fed high fat and sucrose diet
}

\author{
Nwozo SO*, Adeneye DA and Nwawuba SU \\ Nutritional and Industrial Biochemistry Unit, Department of Biochemistry, College of Medicine, University of Ibadan, Nigeria
}

\begin{abstract}
The aim of the present study is to evaluate the effect of Solanium melongena Fruits supplemented diet on hyperglycemia, overweight, liver function and dyslipidemia in male New Zealand rabbits fed high fat and Sucrose solution diet. A qualitative phytochemical analysis of Solanium melongena fruits extract was performed using standard methods and phytochemical analysis showed presence of saponin, flavonoids, alkaloids, anthraquinones, tannins, steriods and terpenoids. A total of twenty male male New Zealand rabbits with mean weights between $489.00 \pm 8.0$ to $493.00 \pm 10.5 \mathrm{~g}$ were divided into five (5) groups ( $\mathrm{n}=4$ ), normal control group was fed normal rabbit chow and experimental groups were fed high fat diet and 30\% sucrose solution. Body weights, blood sugar levels, key liver enzymes and lipid profile were examined, and the results demonstrated that, diet supplemented with $10 \%$ and $20 \%$ of Solanium melongena fruit possess a hypoglycemic ability, could aid weight reduction, restored liver function and acted as a good regulator of lipid profile levels.
\end{abstract}

\section{Introduction}

Diabetes mellitus is a metabolic disorder characterized by hyperglycemia and alterations in carbohydrate, fat, and protein metabolisms associated with absolute or relative deficiencies in insulin secretion and/or insulin action [1]. Associated with obesity, there is hyperinsulinemia, high circulating triglyceride and low HDL, and alteration in the sensitivity or reactivity of vascular smooth muscle to neurotransmitters and circulating hormones, which may cause or contribute to diabetic vessel complications [2,3]. In diabetes, the plasma cholesterol level is usually elevated and this plays a role in the accelerated development of atherosclerotic vascular disease, which is a major long-term complication of diabetes in humans [4,5]. Reported that it is clear that diets enriched in sugar and fat result in obesity and it is widely recognized that obesity is a major risk factor for several diseases including Diabetes mellitus and cardiovascular disease. Recapitulated studies in animal models have shown that exposure to diets that resemble those commonly consumed by human's leads to a marked deterioration in a range of metabolic systems [6]. Diets high in sugar and/or a range of fats including both saturated and polyunsaturated fats invariably leads to excess calorie intake and drives animals toward a positive energy balance concomitant with obesity [5].

Medicinal plants have been used since ancient times for the treatment of different diseases. Currently, medicinal plants continue to play an important role in the management of DM, especially in developing countries, where many people do not have access to conventional anti-diabetic therapies [7]. Ethno-pharmacological surveys indicate that more than 1,200 plants are used in traditional medicine systems following claims of their hypoglycemic properties $[8,9]$.

Solanum species (eggplants) belong to the family of Solanaceae and the plant genus Solanum. Solanum melongena is an economically important vegetable crop that is widely cultivated in the tropical [10]. The leaves and fruits serve as vegetables and are used in traditional medicine [11]. The extracts of Solanum melongena has been shown to be effective against a number of diseases, Antidiabetic [1], as an antioxidant [12], hypolipidaemic agent [13], Anti-inflammatory and Vasodilator [14]. Studies revealed that Solanum melongena eggplant possess key bioflavonoids, phytochemicals and vitamins alike. Flavonoids, total phenolic, alkaloids, saponins, anthraquinones, tannins, vitamin, A, B, C and E $[10,12]$ and this constituent makes Solanum melongena eggplant a potent candidate in abrogating various disease conditions and oxidative imbalance. The nutraceutical power of Solanum melongena fruit has been extensively evaluated and rightly made it imperative to investigate it effect on hyperglycemia and dyslipidemia with focus on diet supplementation which is the predominant way of consuming eggplant rather than using the extract from various solvents as reported in existing literatures.

\section{Materials and method}

\section{Collection and preparation of plant material}

The Solanum melongena fruits were obtained from a farmland at Iseyin, Oyo state and were identified by a botanist in the department of botany, University of Ibadan, Oyo state, Nigeria. The samples were washed with water, sliced into pieces, dried at room temperature for three weeks, grounded into powder, then pelletized as feeds for the experimental animals and stored in an air tight container for further use.

${ }^{\star}$ Correspondence to: Nwozo SO, Nutritional and Industrial Biochemistry Unit, Department of Biochemistry, College of Medicine, University of Ibadan, Ibadan, Oyo State, Nigeria, E-mail: sonwozo@yahoomail.com / onyenibe.nwozo@mail. ui.eu.ng

Received: August 08, 2018; Accepted: August 17, 2018; Published: August 22 2018 
Nwozo SO (2018) Effect of Solanium melongena fruits supplemented diet on hyperglycemia, overweight, liver function and dyslipidemia in male New Zealand rabbits fed high fat and sucrose diet

\section{Phytochemical screening}

Phytochemical screening of Solanum melongena fruits was performed by standard methods according to $[15,16]$.

\section{Experimental animals}

Twenty (20) male rabbits (New Zealand) with the average weight of $490 \mathrm{~g}$ were obtained from Abayomi Farm at Ogbomosho. The animals were allowed to acclimatize for two weeks under standard laboratory condition. During this period of acclimatization, they were fed with standard rabbit chow and allowed free access to clean drinking water.

\section{Preparation of high fat diet}

High fat diet was prepared according to method of [17] some with slight modifications (Table 1).

\section{Supplemented feed preparation}

The eggplant Solanum melongena sample was supplemented into normal diet at two different concentrations (10\% and 20\%). $10 \%$ eggplant supplemented diet had $10 \mathrm{~g}$ of the eggplant sample mixed with $90 \mathrm{~g}$ of normal diet while $20 \mathrm{~g}$ of the sample was mixed with $80 \mathrm{~g}$ of the normal diet for $20 \%$ supplementation. These were thoroughly mixed and made into pellets.

\section{Induction of diabetes and overweight}

The experimental animals were fed with the formulated high fat diet and 30\% sucrose solution for the period of three (3) weeks.

\section{Study design}

A total of twenty (20) rabbits were used for this study, the animals were randomly grouped into 5 groups with four (4) animals in each group.

Group A: Normal control fed with normal diet

Group B: Positive control Fed with high fat diet and 30\% sucrose solution for 6 weeks and treated with $20 \mathrm{mg} / \mathrm{kg}$ Simvastatin for a period of three (3) weeks

Group C: Negative Control Fed with high fat diet and 30\% sucrose solution for 6 weeks and remained untreated.

Group D: Fed with high fat and 30\% sucrose solution for 6 weeks and subsequently with normal diet supplemented with $10 \%$ Solanum melongena for 3 weeks

Group E: Fed with high fat and sucrose solution for 6 weeks and subsequently with normal diet supplemented with $20 \%$ Solanum melongena for 3 weeks

\section{Blood Sugar level and Biochemical Analysis}

Blood glucose level was measured using ACCU-CHEK glucometer. RANDOX kit method of enzymatic hydrolysis described by [18] was used for estimating triglyceride, total cholesterol and high density lipoprotein-cholesterol. Alanine aminotransferase (ALT) and Aspartate aminotransferase (AST) were determined using RANDOX kit a method described by [19]. Alkaline phosphatase was determined by standard method according to the recommendation of [20].

\section{Statistical analysis}

Data were treated by ANOVA (analysis of variance) and mean separation was done using Duncan multiple range test and Turkey. Paired T-test was used to establish difference in timely events. $\mathrm{p}<0.05$ were considered significant. Data was expressed as means \pm standard deviation and pictorially presented in form of charts. All statistical analysis was done using IBM SPSS Version 22 and Microsoft Excel.

\section{Results}

Qualitative Phytochemical analysis of Solanum melongena fruit extract (Table 2) showed positive results for seven (7) out of eight (8) phytochemical tests. Namely: Saponin, Flavonoids, Alkaloids, Anthraquinones, Tannins, Steriods and Terpenoids respectively.

Table 3 shows the hypoglycemic ability of Solanum melongena (eggplant) supplemented feed. Fasting blood sugar levels (FBSL) was measured prior to exposure to high fat diet (HFD) $+30 \%$ Sucrose solution represented as baseline and no significant difference $p>0.05$ was observed between all the groups A, B, C, D and E respectively. After exposure to HFD+Sucrose for a period of 6weeks FBSL was also determined and the experimental groups (A, B, C and D) was significantly higher $\mathrm{p}<0.05$ relative to the normal control (Group A). Following confirmation of hyperglycemia, the FBSL was measured on weekly intervals and they was no significant difference $p>0.05$ between the experimental group at the end of week one. However, at end of week two and three FBSL was significantly lowered in $20 \%$ S. melongena supplemented fed group (E) relative to the Negative control (group C)

Table 4 demonstrates the weight reduction ability of Solanum melongena (eggplant) supplemented feed. Baseline body weight was determined and no significant difference $p>0.05$ was observed between all groups A, B, C, D and E respectively. After HFD + sucrose exposure, the body weight of experimental groups significantly increased $p<005$ relative to the normal control (Group A). Treatment followed for a period of three weeks and at the end of week one, they were no significant $\mathrm{p}>0.05$ weight reduction observed however, at the end of week two and three the body weight was significantly reduced in the group fed $20 \%$ S. melongena (group E) and the positive control (group $\mathrm{B})$ respectively relative to the negative control (group C).

Table 1. Feed composition of normal and high fat diet

\begin{tabular}{|c|c|c|}
\hline Composition & Normal diet (\%) & High Fat diet (\%) \\
\hline Maize & 20 & 18 \\
\hline Soya bean meal & 10 & 9 \\
\hline Wheat Offal & 30 & 27 \\
\hline Corn bran & 15 & - \\
\hline Palm Kernel cake & 20 & 18 \\
\hline Bone meal & 3 & 3 \\
\hline Limestone & 2 & 2 \\
\hline Salt & - & 0.3 \\
\hline Grower premix & - & 0.3 \\
\hline Rice bran & - & 12.4 \\
\hline Pork Lard & - & 10 \\
\hline
\end{tabular}

Table 2. Phytochemical screening of Solanum melongena fruit extract

\begin{tabular}{|l|c|}
\hline Phytochemical & Solanum melongena \\
\hline Saponin & + \\
\hline Flavonoids & +++ \\
\hline Alkaloids & +++ \\
\hline Anthraquinones & ++ \\
\hline Cardiac glycosides & - \\
\hline Tannins & + \\
\hline Steroids & + \\
\hline Terpenoids & + \\
\hline
\end{tabular}

$(+)$ indicates presence in trace amount, $(++)$ indicates presence in moderate amount, $(+++)$ indicates presence in strong amount, and (-) indicates not detected. 
Nwozo SO (2018) Effect of Solanium melongena fruits supplemented diet on hyperglycemia, overweight, liver function and dyslipidemia in male New Zealand rabbits fed high fat and sucrose diet

Table 3. Effect of Solanum melongena (eggplant) supplemented feed on the mean fasting blood glucose level of male New Zealand Rabbits

\begin{tabular}{|c|c|c|c|c|c|}
\hline \multirow{2}{*}{ Groups } & \multirow{2}{*}{ Baseline (mg/dl) } & \multirow{2}{*}{ HFD+Sucrose (mg/dl) } & \multicolumn{3}{|c|}{ Feed supplementation duration } \\
\hline & & & Week $1(\mathrm{mg} / \mathrm{dl})$ & Week $2(\mathrm{mg} / \mathrm{dl})$ & Week $3(\mathrm{mg} / \mathrm{dl})$ \\
\hline $\mathbf{A}$ & $68.75 \pm 3.4^{\mathrm{a}}$ & $72.75 \pm 2.9^{\mathrm{a}}$ & $72.50 \pm 1.9^{\mathrm{a}}$ & $72.75 \pm 4.5^{\mathrm{a}}$ & $71.75 \pm 2.9^{\mathrm{a}}$ \\
\hline B & $65.50 \pm 9.0^{\mathrm{a}}$ & $195.00 \pm 4.8^{\mathrm{b}}$ & $191.25 \pm 4.6^{\mathbf{b c}}$ & $172.75 \pm 7.4^{\mathrm{bc}}$ & $161.75 \pm 5.9^{c}$ \\
\hline $\mathbf{C}$ & $66.25 \pm 6.3^{\mathrm{a}}$ & $194.75 \pm 4.8^{\mathrm{b}}$ & $207.75 \pm 7.1^{\mathrm{c}}$ & $204.73 \pm 6.6^{\mathrm{d}}$ & $205.50 \pm 9.7^{\mathrm{d}}$ \\
\hline D & $71.50 \pm 2.5^{\mathrm{a}}$ & $193.25 \pm 8.7^{\mathrm{b}}$ & $191.00 \pm 10.8^{\text {be }}$ & $181.25 \pm 11.2^{\mathrm{c}}$ & $157.75 \pm 13.1^{\mathrm{c}}$ \\
\hline $\mathbf{E}$ & $68.50 \pm 6.6^{\mathrm{a}}$ & $196.75 \pm 11.5^{\mathrm{b}}$ & $188.50 \pm 11.1^{\mathrm{b}}$ & $153.00 \pm 12.9^{b}$ & $112.75 \pm 8.5^{b}$ \\
\hline
\end{tabular}

Data are expressed as means \pm SD: Means with different alphabet as superscript within each column variable are considered significantly ( $<0.05$ ). The abbreviations denote HFD: high fat diet, A: Normal control, B: Positive control, C: Negative control, D: $10 \%$ S. melongena, E: $20 \%$ S. melongena

Table 4. Effect of Solanum melongena (eggplant) supplemented feed on body weights of male New Zealand Rabbits

\begin{tabular}{|c|c|c|c|c|c|}
\hline \multirow{2}{*}{ Groups } & \multirow{2}{*}{ Baseline (g) } & \multirow{2}{*}{ HFD+Sucrose (g) } & \multicolumn{3}{|c|}{ Feed supplementation duration } \\
\hline & & & Week 1 (g) & Week 2 (g) & Week $3(\mathrm{~g})$ \\
\hline $\mathbf{A}$ & $489.00 \pm 8^{\mathrm{a}}$ & $804.50 \pm 10.2^{\mathrm{a}}$ & $819.50 \pm 10.3^{\mathrm{a}}$ & $843.75 \pm 15.2^{\mathrm{a}}$ & $864.75 \pm 5.7^{\mathrm{a}}$ \\
\hline B & $489.25 \pm 15.2^{\mathrm{a}}$ & $1332.5 \pm 46.7^{\mathbf{b}}$ & $1351.25 \pm 57.8^{\mathbf{b}}$ & $1220.50 \pm 53.4^{b}$ & $1196.75 \pm 61.5^{\mathrm{b}}$ \\
\hline $\mathbf{C}$ & $492.25 \pm 15.6^{\mathrm{a}}$ & $1349.5 \pm 42.6^{\mathrm{b}}$ & $1376.00 \pm 45.3^{b}$ & $1489.5 \pm 39.9^{c}$ & $1508.00 \pm 39.6^{\mathrm{d}}$ \\
\hline D & $486.75 \pm 10.5^{\mathrm{a}}$ & $1369.75 \pm 46.4^{\mathrm{b}}$ & $1385.00 \pm 47.1^{\mathrm{b}}$ & $1447.00 \pm 82.8^{\mathrm{c}}$ & $1346.75 \pm 49.6^{\mathrm{c}}$ \\
\hline $\mathbf{E}$ & $493.00 \pm 10.5^{\mathrm{a}}$ & $1389.00 \pm 9.6^{\mathrm{b}}$ & $1400.25 \pm 12.5^{\mathrm{b}}$ & $1254.75 \pm 11.3^{\mathrm{b}}$ & $1247.75 \pm 10.1^{\mathrm{b}}$ \\
\hline
\end{tabular}

Data are expressed as means \pm SD: Means with different alphabet as superscript within each column variable are considered significantly (p $<0.05$ ). The abbreviations denote HFD: high fat diet, A: Normal control, B: Positive control, C: Negative control, D: $10 \%$ S. melongena, E: $20 \%$ S. melongena

\section{Liver enzyme}

Figure 1 shows effect of S.melongena on liver function. At the end of week three of supplemented diet feeding, serum levels of liver enzymes AST, ALT and ALP was respectively was assayed for and they negative control that remained untretaed had a significant increase $\mathrm{p}<0.05$ in all the enzyme levels relative to the normal control. for AST, $10 \%$ and $20 \%$ S.melongena supplemented diet fed groups and the positive control significantly showed a decrease levels of AST relative to the negative control (group B). however, 20\% S.melongena supplemented diet fed group significantly reduced $\mathrm{p}<0.05$ levels of ALT and ALP respectively when compared to the $10 \%$ S.melongena supplemented diet fed group which was signifcantly lower than the negative control.

\section{Lipid profile}

Figures 2, 3 and 4 respectively shows the effect of Solanum melongena (eggplant) supplemented diet on lipid profile levels. Baseline serum levels of Cholesterol (CHOL), Triglyceride (TRIG) and High Density Lipoprotein (HDL) was determined and they was no significant difference $\mathrm{p}>0.05$ between all groups and after exposure to HFD+30\% Sucrose for 6 weeks, the experimental groups showed a significant change $\mathrm{p}<0.05$ in lipid profile levels relative to the baseline. Treatment followed for another 3 weeks, $20 \%$ and $10 \%$ S.melongena supplemented diet fed groups and the positive control significantly lowered $\mathrm{p}<0.05$ levels of CHOL and TRIG relative to after HFD $+30 \%$ Sucrose. However, HDL levels were significantly increased $\mathrm{p}<0.05$ in the treated groups.

\section{Discussion}

The present study tried to established hyperglycemia and overweight by feeding male New Zealand rabbits with a formulated high fat diet and $30 \%$ sucrose solution a model previously shown to be effective in rabbits and other experimental animals a well $[5,21,22]$. The result of this study table 3 showed that the formulated high fat diet with $30 \%$ sucrose solution (HFD+Sucrose) caused a frank hyperglycemia as they was a significant increase $\mathrm{p}<0.05$ in fasting blood sugar levels (FBSL) in the experimental group relative to the normal control and this indicates that high-fat-/high-sucrose-induced diabetes could have arisen from conjunct effect of lipotoxicity and glucotoxicity [21,23]. S. melongena fruits have been shown to be a promising nutraceutical and a

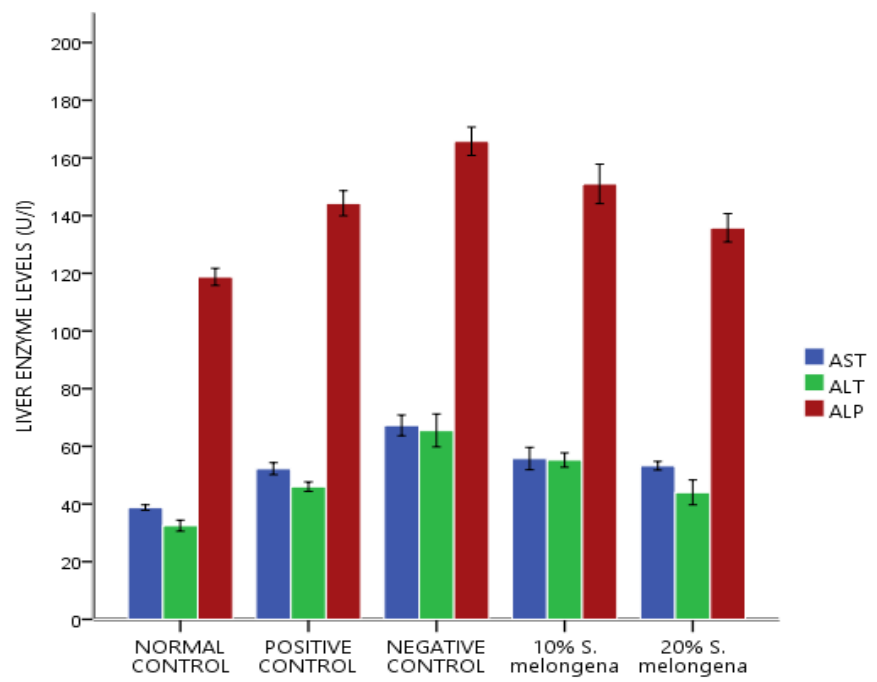

Figure 1. Effect of Solanum melongena (eggplant) supplemented feed on liver enzymes of male New Zealand Rabbits

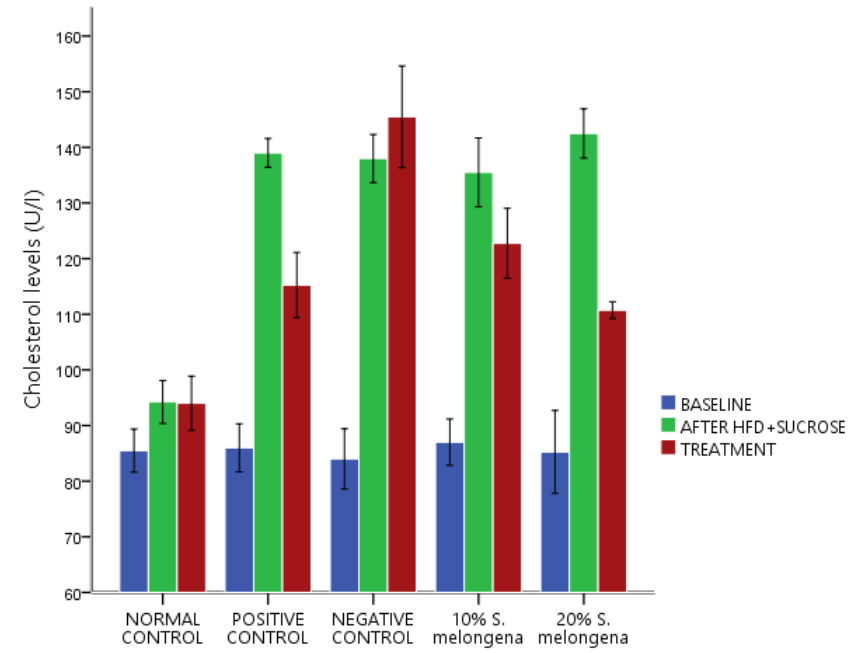

Figure 2. Effect of Solanum melongena (eggplant) supplemented feed on cholesterol levels of male New Zealand Rabbits 


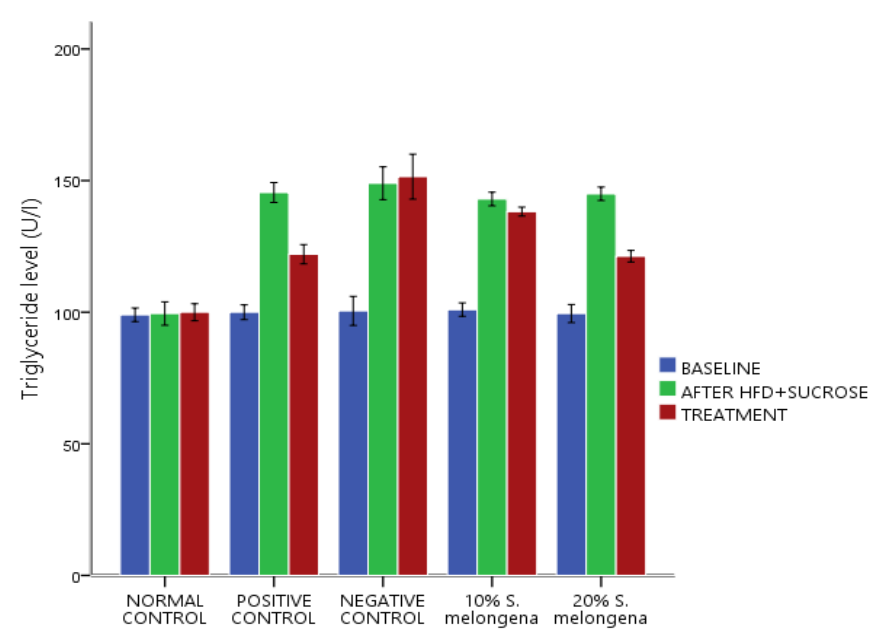

Figure 3. Effect of Solanum melongena (eggplant) supplemented feed on Triglyceride level of male New Zealand Rabbits

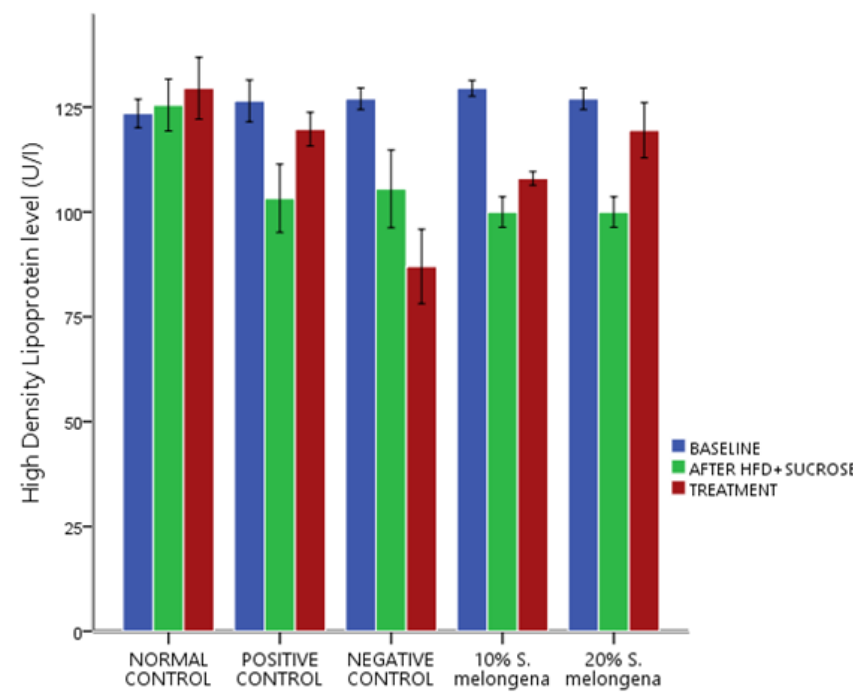

Figure 4. Effect of Solanum melongena (eggplant) supplemented feed on High density lipoprotein levels of male New Zealand Rabbits

potent hypoglycemic agent $[1,24]$. In corroboration, our result revealed that supplementing diet with $S$. melongena fruit is an effecting tool in management of hyperglycemia which characterize diabetes mellitus in that they groups fed both 10 and $20 \%$ S. melongena supplemented diet significantly reduced FBSL particularly at week two and three and this may be attributed to the presence of key phytochemicals and bioflavonoids.

The epidemic of overweight spreading throughout the world represents one of the major challenges for future human health and diets high in sugar and/or a range of fats including both saturated and polyunsaturated fats invariably leads to excess calorie intake and drives animals toward a positive energy balance concomitant with obesity [5] thus our result table 4 demonstrated that formulated high fat diet (Table 1) with $30 \%$ sucrose solution resulted to obvious weight gain an indicator of overweight as they was a significant increase $\mathrm{p}<0.05$ in the body weight of the rabbits in the experimental groups after 6 weeks of feeding relative to the normal control. However, following supplementation of the diet with $10 \%$ and $20 \%$ of S. melongena the body weight was significantly reduced similar to the positive control treated with $20 \mathrm{mg} / \mathrm{kg}$ Simvastatin and perhaps reduce the chance of diabetes and other related diseases.

Enzyme activities in the tissues are often used as 'marker' to ascertain early toxic effects of administered foreign compounds to experimental animals [25]. ALP is a membrane bound enzyme while ALT and AST are cytosolic enzymes and high levels of ALP, ALT and AST respectively in the serum are indicators of cell membrane permeability and consequent degree of damage to the liver [26]. The observed significant $\mathrm{p}<0.05$ increase in the serum levels of liver enzymes (ALP, ALT, AST) figure 1 in the negative control relative to the normal control indicates that HFD $+30 \%$ sucrose solution may also be a key player of hepatocellular damage. However, diet supplementation with $10 \%$ and $20 \%$ of S. melongena was able to lower the levels of liver enzymes in male New Zealand Rabbits.

Feeding a carbohydrate- and fat-rich dietary components have been used in animals to induce the signs and symptoms of human metabolic syndrome $[27,28]$ and high serum triglycerides and low High-Density Lipoprotein (HDL) levels are listed among the clustering medical conditions related to metabolic syndrome [29]. Thus, our findings figures 2,3 and 4 respectively demonstrated an alteration in the levels of CHOL, TRIG and HDL after high fat diet and 30\% sucrose solution feeding for 6 weeks. However, following supplementation of the diet with $10 \%$ and $20 \%$ of S. melongena, CHOL and TRIG levels were significantly reduced, and HDL levels was significantly increased similar to the positive control treated with $20 \mathrm{mg} / \mathrm{kg}$ Simvastatin and our result is in consistent with the report of $[13,14]$.

\section{Conclusion}

Our result demonstrates that diet supplemented with $10 \%$ and $20 \%$ of $S$. melongena fruit possess a hypoglycemic ability, aid weight reduction, restores the function of the liver and acts a good regulator of lipid profile levels in male New Zealand Rabbits. However, further studies are still needed to characterize and isolate the potent compound responsible for it positive effect.

\section{Acknowledgment}

The authors are very grateful to Nutritional and Industrial Unit, Department of Biochemistry, University of Ibadan for providing the material resources and an enabling environment for the successful completion of this study.

\section{References}

1. Sohrabipour S, Fatemah K, Nepton S, Mohammad K (2013) Effect of the administration of Solanum nigrum fruit on blood glucose, lipid profiles, and sensitivity of the vascular mesenteric bed to phenylephrine in streptozotocin-induced diabetic rats. Med Sci Monit Basic Res 19: 133-140. [Crossref]

2. Ceriello A (2005) Postprandial hyperglycemia and diabetes complications: is it time to treat? Diabetes 54: 1-7. [Crossref]

3. Farsi L, Keshavarz M, Soltani N (2010) Relaxatory effect of GABA mediated by same pathway in diabetic and normal rat vessel. Iran Basic Med Sci 4: 94-98.

4. Jenkins AJ, Lyons T, Zheng DY (2003) Serum lipoproteins in the diabetes control and complications trial/epidemiology of diabetes intervention and complications cohortAssociations with gender and glycemia. Diabetes Care 26: 810-818. [Crossref]

5. Burchfield JG, Melkam AK, Christopher CM, Jacqueline SP, Tess W, et al. (2018) High dietary fat and sucrose results in an extensive and time-dependent deterioration in health of multiple physiological systems in mice. J Biol Chem 293: 5731-5745. [Crossref]

6. Buettner R, Scholmerich J, Bollheimer LC (2007) High-fat diets: modeling the metabolic disorders of human obesity in rodents. Obesity (Silver Spring) 15: 798-808. [Crossref] 
Nwozo SO (2018) Effect of Solanium melongena fruits supplemented diet on hyperglycemia, overweight, liver function and dyslipidemia in male New Zealand rabbits fed high fat and sucrose diet

7. Chikezie PC, Ojiako OA, Nwufo KC (2015) Overview of Anti-Diabetic Medicinal Plants: The Nigerian Research Experience. J Diabetes Metab 6: 1-7.

8. Grover JK, Yadav S, Vats V (2002) Medicinal plants of India with anti-diabetic potential. J Ethnopharmacol 81: 81-100. [Crossref]

9. Dey L, Attele AS, Yuan CS (2002) Alternative therapies for type 2 diabetes. Altern Med Rev 7: 45-58. [Crossref]

10. Agoreyo BO, Obansa ES, Obanor EO (2012) Comparative nutritional and phytochemical analysis of two varieties of Solanum melongena. Sci World J 7: 5-8.

11. Bonsu KO, Fontem DA, Nkansah GO, Iruome RN, Owusu, EO, et al. (2008) Diversity within the gboma eggplant (Solanum marcocarpon), an indigenous vegetable from West Africa. Ghana J Horticulture 1: 50-58.

12. Mbah UO, and Egbuonu ACC (2017) Ethanolic Extract of Solanum melongena Linn Fruit Mitigated Monosodium Glutamate-Induced Oxidative Stress. Int J Biochem Res Rev 18: 1-8.

13. Ossamulu IF, Akanya HO, Jigam AA, Egwin EC, Adeyemi HY (2014) Hypolipidemic properties of four varieties of egg plants (Solanum melongena L.). Int J Pharma Sci Invent 3: 47-54

14. Poongothai K, Syed ZK, Ponmurugan P, Jayanthi M (2010) Assessment of antidiabetic and antihyperlipidemic potential of Solanum nigrum and Musa paradisiaca in alloxan induced diabetic rats. $J$ Pharmacy Res 3: 2203-2205.

15. Harbone JB (1998) Phytochemical methods-A guide to modern techniques of plants analysis. Champman and Hall, London. pp: 182-190.

16. Allen GM, Nostro A, Germano MP, Marino A, Cannatelli MA (1974) Extraction Methods and Bioautography for evaluation of Medicinal plant. Lett Appl Microbiol 30: 379-384. [Crossref]

17. Yin W, Yuan Z, Wang Z, Yang B, Yang Y (2002) A diet high in saturated fat and sucrose alters glucoregulation and induces aortic fatty streaks in New Zealand white rabbits. Int J Exp Diabetes Res 3: 179-184. [Crossref]

18. Richmond W (1973) Preparation and properties of a cholesterol oxidase from Nocardia specie and its application to the enzymatic assay of total cholesterol in serum. Clin Chem 19: 1350-1356. [Crossref]
19. Reitman S, Frankel S (1957) A colorimetric method for the determination of serum glutamic oxalacetic and glutamic pyruvic transaminases. Am J Clin Pathol 28: 56-63. [Crossref]

20. Englehardt A (1970) Measurement of alkaline phosphatase. Aerztl Labor 16: 42-43.

21. Xi S, Yin W, Wang Z, Kusunoki M, Lian X, et al. (2004) A minipig model of high-fat/ high-sucrose diet-induced diabetes and atherosclerosis. Int J Exp Pathol 85: 223-231. [Crossref]

22. Chalkley SM, Hettiarachchi M, Chisholm DJ, Kraegen EW (2002) Long-term high-fat feeding leads to severe insulin resistance but not diabetes in Wistar rats. Am J Physiol Endocrinol Metab 282: E1231-E1238. [Crossref]

23. Poitout V, and Robertson RP (2002) Minireview: Secondary betacell failure in type 2 diabetes-a convergence of glucotoxicity and lipotoxicity. Endocrinology 143: 339-342. [Crossref]

24. Nwanna EE, Emmanuel O, Ibukun, Ganiyu O (2016) Effect of some tropical eggplan fruits (Solanum Spp) supplemented diet on diabetic neuropathy in male Wistar rats invivo. Funct Foods Health Dis 6: 661-676.

25. Adesokan AA, Oyewole OI, Turay MS (2009) Kidney and Liver Function Parameter in Alloxan-Induced Diabetic Rats Treated with Aloe Barbadensis Juice Extract. Sierra Leone J Biomed Res 1: 33-37.

26. Cotran R, Kumar V, Robins S (1989) Robin's pathological basis of disease. (4 ${ }^{\text {th }}$ edn), W.B Saunders Co, Harcourt: 212-217.

27. Ragab SM, Sary K, Elghaffar A, Tarek H, El-Metwally, et al. (2015) Effect of a high fat, high sucrose diet on the promotion of non-alcoholic fatty liver disease in male rats: the ameliorative role of three natural compounds. Lipids Health Dis 14: 2-11.

28. Panchal SK, Brown L (2011) Rodent models for metabolic syndrome research. $J$ Biomed Biotechnol 2011: 351982. [Crossref]

29. Falkner B, Cossrow ND (2014) Prevalence of metabolic syndrome and obesityassociated hypertension in the racial ethnic minorities of the United States. Curr Hypertens Rep 16: 449. [Crossref]

Copyright: (C2018 Nwozo SO. This is an open-access article distributed under the terms of the Creative Commons Attribution License, which permits unrestricted use, distribution, and reproduction in any medium, provided the original author and source are credited. 